\title{
Meridiano 82
}

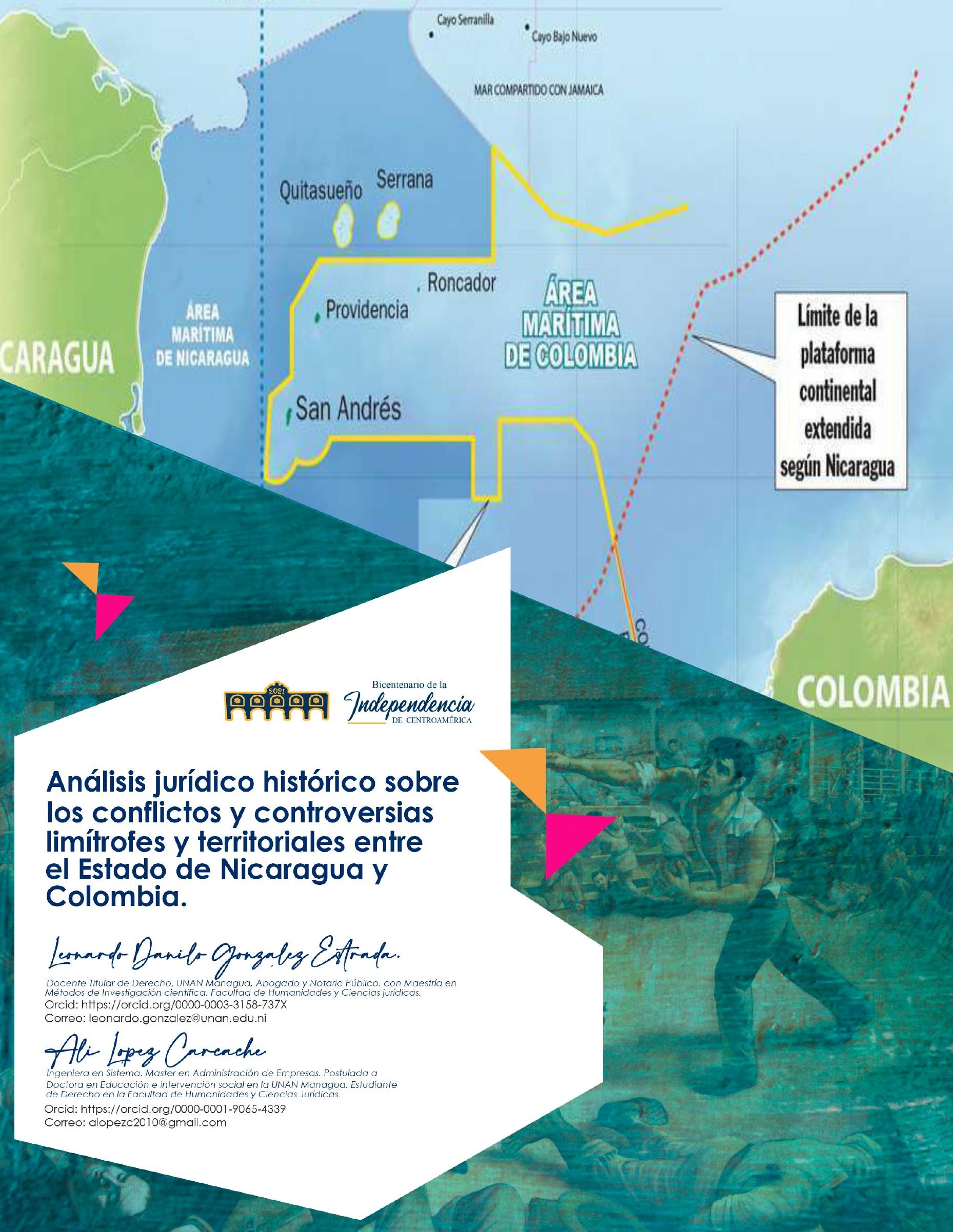




\section{Análisis jurídico histórico sobre los conflictos y controversias limítrofes y territoriales entre el Estado de Nicaragua y Colombia.}

Historical legal analysis of border and territorial conflicts and controversies between the State of Nicaragua and Colombia.

\section{RESUMEN}

La presente investigación jurídica es una sistematización jurídica en el Derecho internacional público, a partir de las controversias entre el Estado de Nicaragua y de Colombia, derivadas, de los procesos colonialistas, tanto de los Estados Unidos de Norte América y Gran Bretaña, hegemonías jurídicas y militares, que se disputaban el territorio geo estratégico de los nicaragüenses, de Centroamérica, como de la plataforma marítima del océano Atlántico, para sostener su poder Imperial capitalista. Teniendo un desenlace a favor del Estado de Nicaragua, a partir de la Revolución Popular Sandinista el 19 de julio de 1979, en tanto Nicaragua se convierte en una Estado respetuoso del Derecho internacional y diplomático, a partir de la defensa de su soberanía y autodeterminación jurídico política, cuya síntesis para esta controversia fue la sentencia de la Corte Internacional de Justicia en la ONU, el 19 de noviembre de 2012. En este artículo se explicará con rigurosidad, la evolución desde el propio origen del problema, que tuvo un abordaje desde el derecho internacional público, en el ordenamiento jurisdiccional competente para dirimirlo.

\section{ABSTRACT}

This legal investigation is a legal systematization in public international law, based on the controversies between the State of Nicaragua and Colombia, derived from the colonialist processes, both in the United States of North America and Great Britain, legal hegemonies and military, who disputed the geo-strategic territory of the Nicaraguans, of Central America, as well as the maritime platform of the Atlantic Ocean, to sustain their Imperial capitalist power. Having an outcome in favor of the State of Nicaragua, starting with the Sandinista Popular Revolution on July 19, 1979, while Nicaragua becomes a State that respects international and diplomatic law, based on the defense of its sovereignty and legal self-determination. policy, whose synthesis for this controversy was the ruling of the International Court of Justice at the UN, on November 19, 2012. This article will rigorously explain the evolution from the very origin of the problem, which had an approach from the public international law, in the competent jurisdictional order to resolve it.

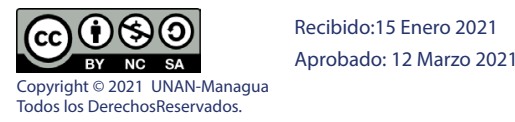

\section{PALABRAS CLAVE}

Nicaragua, Colombia, Controversia maritima, Corte Internacional de Justicia, Derecho Internacional Público, Sistematización Jurídica.

\section{KEYWORDS}

Nicaragua, Colombia, Maritime

Controversy, International Court of

Justice, Public International Law, Legal

Systematization. 


\section{Introducción.}

Es relevante que el análisis sobre problemas de derecho internacional público y geopolítica, sean actualizados sobre todo desde métodos jurídicos, además con las dimensiones propias del derecho internacional, en tanto la historia de los estados, su geografía, sus propios procesos políticos, como capacidades geo económicas, se determinan desde sus condiciones específicas locales o a partir de los procesos globales, colonialista o neocolonialistas.

Por lo anterior el fundamento de la presente sistematización es según la propuesta epistémica jurídica de Witker y Larios (1997, pág. 186) que proponen que en esta metodología se recurre para interpretar e investigar el derecho en dos elementos: i) tipificar la institución jurídica, a la cual debe ser referida la norma para su análisis e interpretación, ii) determinar el alcance de la norma interpretada, en función de la institución a la cual pertenece.

En tal sentido, esta sistematización jurídica sobre interpretar e investigar las normas e instituciones en derecho internacional público, a partir del derecho de los tratados y resoluciones con efectos extraterritoriales, en tres momentos y plazos culturales históricos, el siglo 19, cuyo colonialismo delimitó territorios y poder político económico sobre el Estado de Nicaragua, donde el Imperio Español dicta la Orden Real en 1803, otorgando a Colombia derechos extraterritoriales, por otro tanto, en el siglo 20 donde se propone un nuevo eje jurídico internacional pujado por Estados Unidos de Norteamérica y Gran Bretaña. Imperios jurídicos, por su hegemonía militar, que no tomaban en cuenta la autodeterminación y soberanía de las Naciones, sin embargo en Nicaragua, aconteció que su población adquirió conciencia histórica y tomó el poder del Estado en julio de 1979, que en el ámbito del derecho internacional determinó una nueva configuración geopolítica, económica y geo-cultural, puesto que el nuevo Estado tendría un nuevo desenlace geopolítica y en el orden del derecho internacional, para el siglo 21, con una sentencia a favor del Estado de Nicaragua en el año de 2012.

En el desarrollo concreto del artículo se describe el surgimiento y evolución del conflicto limítrofe entre Colombia y Nicaragua, a partir de la Real Orden en 1803, hasta la sentencia de la Corte Internacional de Justicia de noviembre de 2012. La investigación se dividen cuatro secciones: antecedentes, cronología del conflicto, proceso legal y consecuencias.

Se presentan a los sujetos del derecho internacional público sobre el diferendo los estados de Nicaragua, Colombia y como terceros países como Estados Unidos, Inglaterra, Honduras y Costa Rica, que fueron los precursores de la demanda y de la resolución de la Corte Internacional de Justicia, abarcando desde el periodo de 1803 hasta inicios de1980.

El análisis, interpretación y procesos estratégicos entre los Estados parte sobre los instrumentos jurídicos como fuentes del derecho los Tratados y Resoluciones, la Orden Real 1803y 1806, Ley de Guano de los EEUU (1856), el Decreto No. 205, Decreto No. 324 (1980) el Tratado Chamorro Bryan (1914), Chamorro Weitzel (1913), el Tratado Bárcenas Esguerra (1928), como el tratado Tratado Saccio Vázquez Carrizosa (1981), para mencionar parte principal del cauce jurídico, para la resolución que la Corte Internacional de Justicia considerará para dirimir la controversia marítima entre los Estados. En este sentido se explicará el proceso ante la Haya, algunas estrategias de litigación internacional, para la defensa de las pretensiones tanto de Nicaragua como del Estado de Colombia. 


\section{Desarrollo}

\subsection{Antecedentes}

Como los antecedes entre el conflicto entre Nicaragua, Colombia y con terceros países, que fueron los precursores de la controversia y de la resolución de la Corte Internacional de Justicia, abarcando desde el periodo de 1803 hasta finales de las últimas décadas del siglo 20.

La antigua costa de los Mosquitos, incluyendo las islas adyacentes del archipiélago de San Andrés y Providencia que durante la colonia habían permanecido bajo la jurisdicción de la Capitanía General de Guatemala pasaron en 1803, a constituir parte de la jurisdicción del Virreinato de Nueva Granada, que estaba en mejor aptitud para defender la costa del Caribe, desde el castillo de Chagres en Panamá hasta el cabo de Gracias a Dios (Dirección de Relaciones Internacionales Parlamentarias, 2012).

\section{Mapa de la Mosquitia}

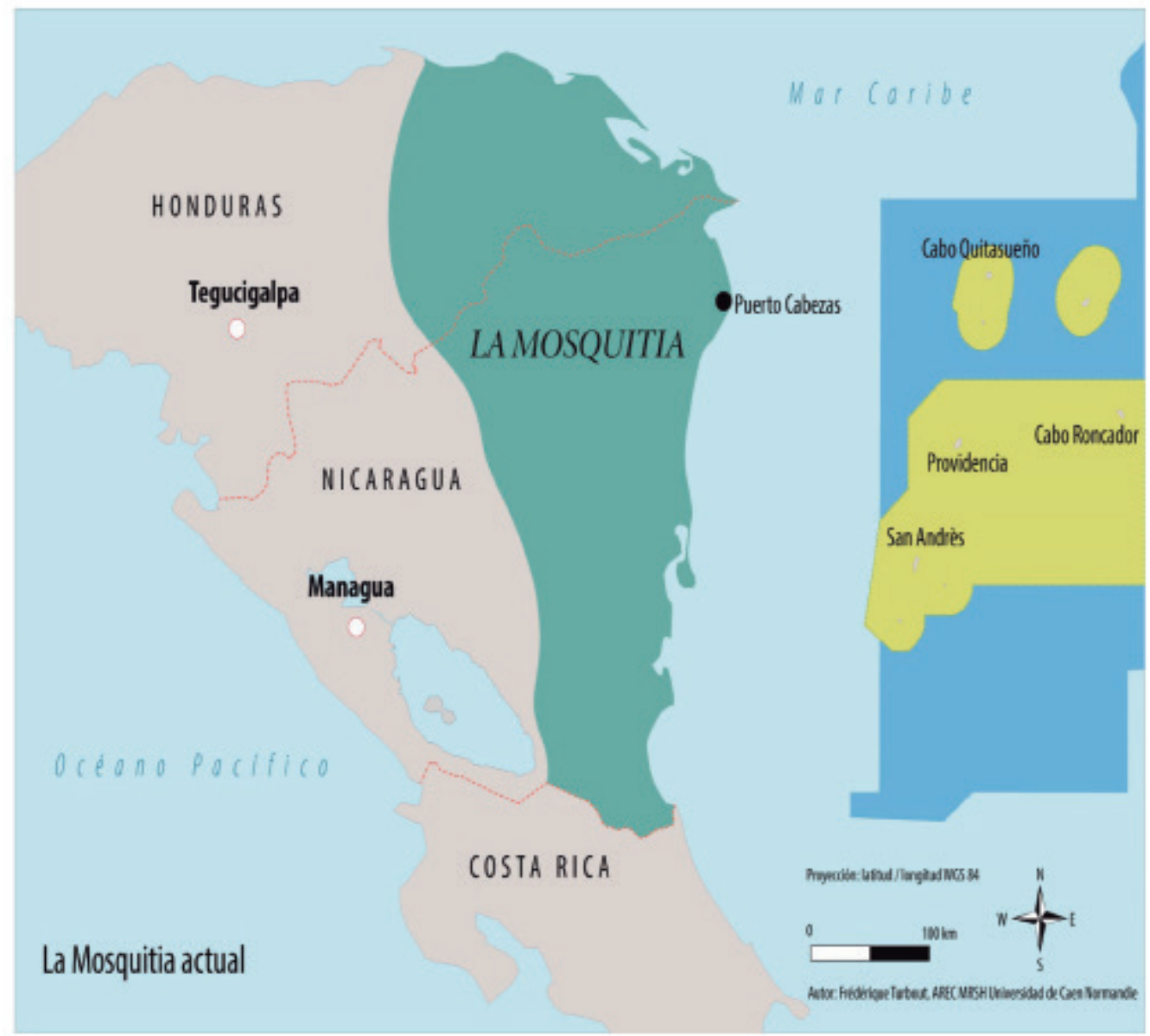

Fuente: (Turbout \& Toro-Pérez, s.f.) 
La Real Orden de noviembre de 1803, que nunca implicó separación de territorios, sino una comisión de vigilancia militar, fue el documento invocado por Colombia para reivindicar supuestos derechos en la Costa Atlántica nicaragüense e islas adyacentes (Dirección de Relaciones Internacionales Parlamentarias, 2012).

La Real Orden de 1803 es una docena de líneas en las que el monarca español establece que "las islas de San Andrés y la parte de la Costa de Mosquitos, desde el cabo Gracias a Dios inclusive hacia el río Chagres, queden segregadas de la Capitanía General de Guatemala y dependientes del Virreinato de Santa Fe" (Bogotá). Esta es la base del litigio (Zamora, 2013).

\section{Firma del Trafado Chamorro-Bryan}

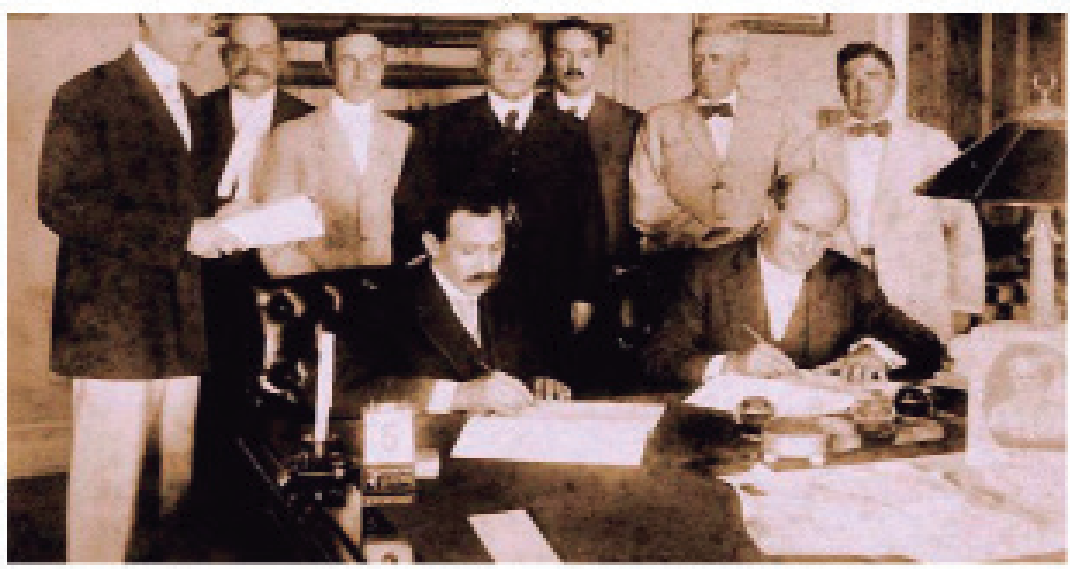

Fuente: (Revista Consenvadora, 1964)

El Capitán General de Guatemala protestó enérgicamente la decisión manifestando que "siempre los establecimientos de Mosquitos han dependido de esta Capitanía General". Solicitaba que las cosas volvieran a su estado anterior. Las razones del Capitán General fueron escuchadas y la Real Orden de 1803 quedó derogada por Real Orden de 1806 (Dirección de Relaciones Internacionales Parlamentarias, 2012).

Un antecedente relevante es el hecho que, en el conflicto entre Colombia y Costa Rica en 1990, el presidente de Francia Emile Loube, fue designado árbitro y falló a favor de Costa Rica, negando la validez de la Real Orden de 1803. Asimismo, el hecho que en el Tratado Altamirano Harrison (1905), Inglaterra reconoce de manera formal la soberanía de Nicaragua sobre la Mosquitia (Dirección de Relaciones Internacionales Parlamentarias, 2012).

Otro hecho relevante es la disputa entre Colombia y Gran Bretaña a lo largo del siglo XIX por el control de la Costa de Mosquitos y el acceso al río San Juan, zonas indispensables para la construcción del canal interoceánico en Nicaragua. La presión inglesa llevó a Colombia a acercarse a los Estados Unidos de América y negociar el Tratado Mallarino-Bidlack en 1846 que uno de sus puntos era "Iniciar una asociación con el Gobierno de Norteamérica para abrir un canal por el río San Juan" (Alvarado Bedoya, 2014).

En 1856 se proclama la Ley de Guano por Estados Unidos que tenía como objetivo proteger la explotación de hacían empresarios norteamericanos del guano como fuente de fosfato para la agricultura, consideraban como propias las Islas Roncador y Quitasueños (Alvarado Bedoya, 2014).

En 1913 Nicaragua arrienda las islas del Mangle (Chico y Grande) por 99 años a los Estados Unidos mediante el Tratado Chamorro - Weitzel (1913) las cuales facilitaban la operación y defensa del canal interoceánico de Panamá. (Dirección de Relaciones Internacionales Parlamentarias, 2012). 
En 1914 se firma el Tratado Chamorro - Bryan en que se le permitía a los Estados Unidos construir un canal interoceánico por el territorio de la costa de los Mosquitos en intercambio que Estados Unidos proporcionó una fuerza militar suficiente para garantizar la estabilidad interna del país. De esta forma el país norteamericano creó de facto un protectorado (Alvarado Bedoya, 2014).

Durante 1924, Nicaragua fue ocupada militar y políticamente por Estados Unidos, con este suceso el gobierno de Colombia inició arreglos secretos con Estados Unidos para que éste obligara a Nicaragua a renunciar a sus derechos de soberanía .

\section{Marines en Nicaragua}

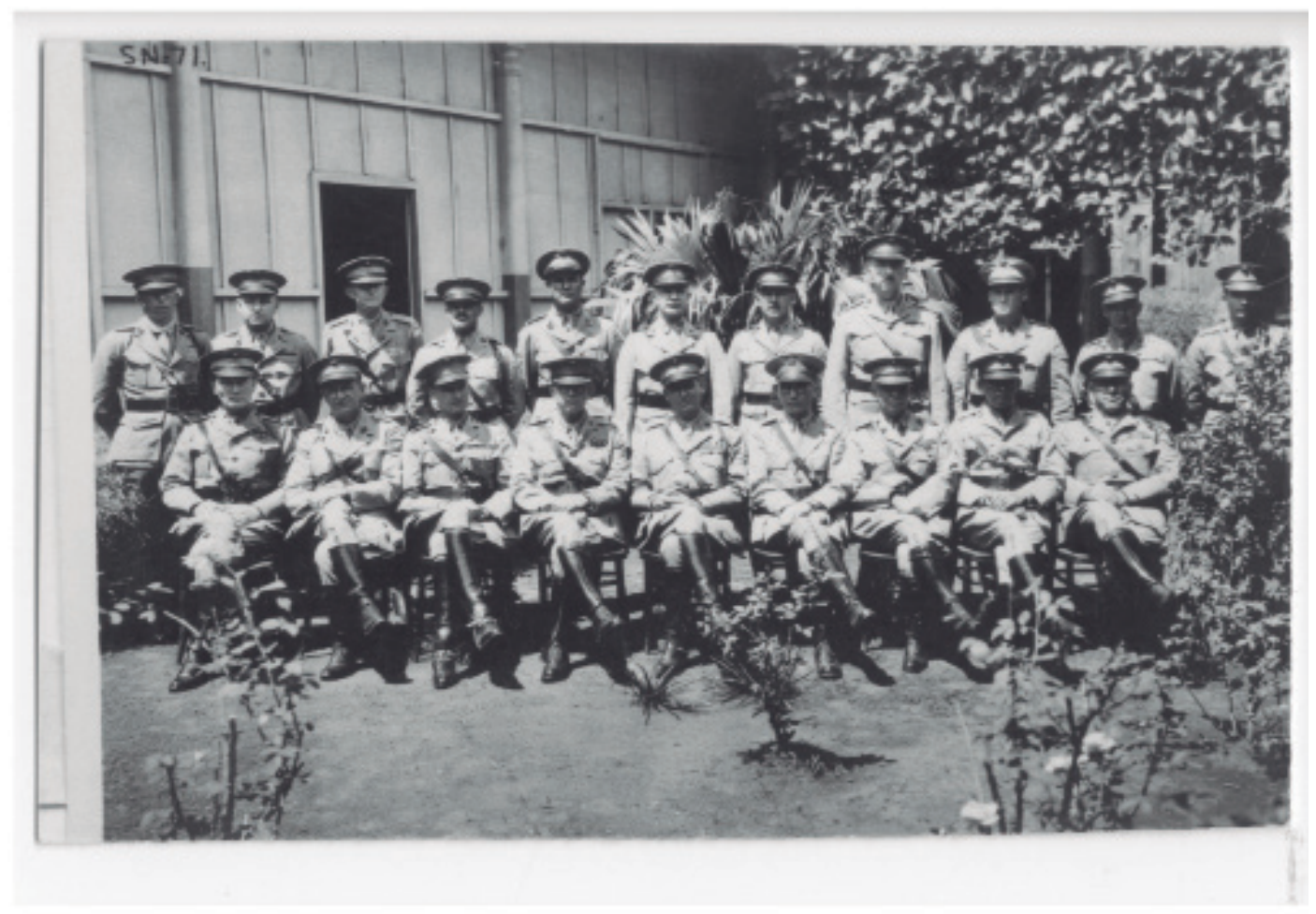

\section{Fiuente: (Navarrete, 2019)}

El 1928 por presión de Estados Unidos las repúblicas de Colombia y Nicaragua suscribieron el Tratado Esguerra Bárcenas, con el objeto de poner término al litigio territorial que se encontraba pendiente entre los dos países en ese momento. Este tratado definió en dos artículos la soberanía colombiana sobre las Islas de San Andrés, Providencia, Santa Catalina y todas las demás islas, islotes y cayos que hacen parte del archipiélago de San Andrés, excluyendo de ese tratado a los cayos Roncador, Quitasueño y Serrana, debido a que en ese momento se encontraban dentro del litigio entre Colombia y los Estados Unidos de América; a su vez, se reconoció el dominio de Nicaragua sobre la costa de Mosquitos comprendida entre el cabo de Gracias a Dios y el río San Juan, y sobre las islas Mangle Grande y Mangle Chico, ubicadas en el Océano Atlántico (Great Corn Island, Little corn island) (Asamblea Nacional, 1928).

Durante 1969, se genera un incidente diplomático entre Colombia y Nicaragua, después que el gobierno de Nicaragua otorgara concesiones de exploración petrolera más allá del meridiano 82" en 1964 a la Union Oil, en 1966 a la Mobil Oil, en 1965 a la Shell y en 1967 a la Chevron (Zamora, 2013). 
Colombia suscribió con Estados Unidos el Tratado Saccio-Vázquez Carrizosa, en 1972, por el cual Estados Unidos cedía y traspasaba la soberanía de los cayos y bancos de Roncador, Serrana y Quitasueño a Colombia, poniendo fin de esa manera a lo acordado en las notas Olaya-Kellog del 1928.

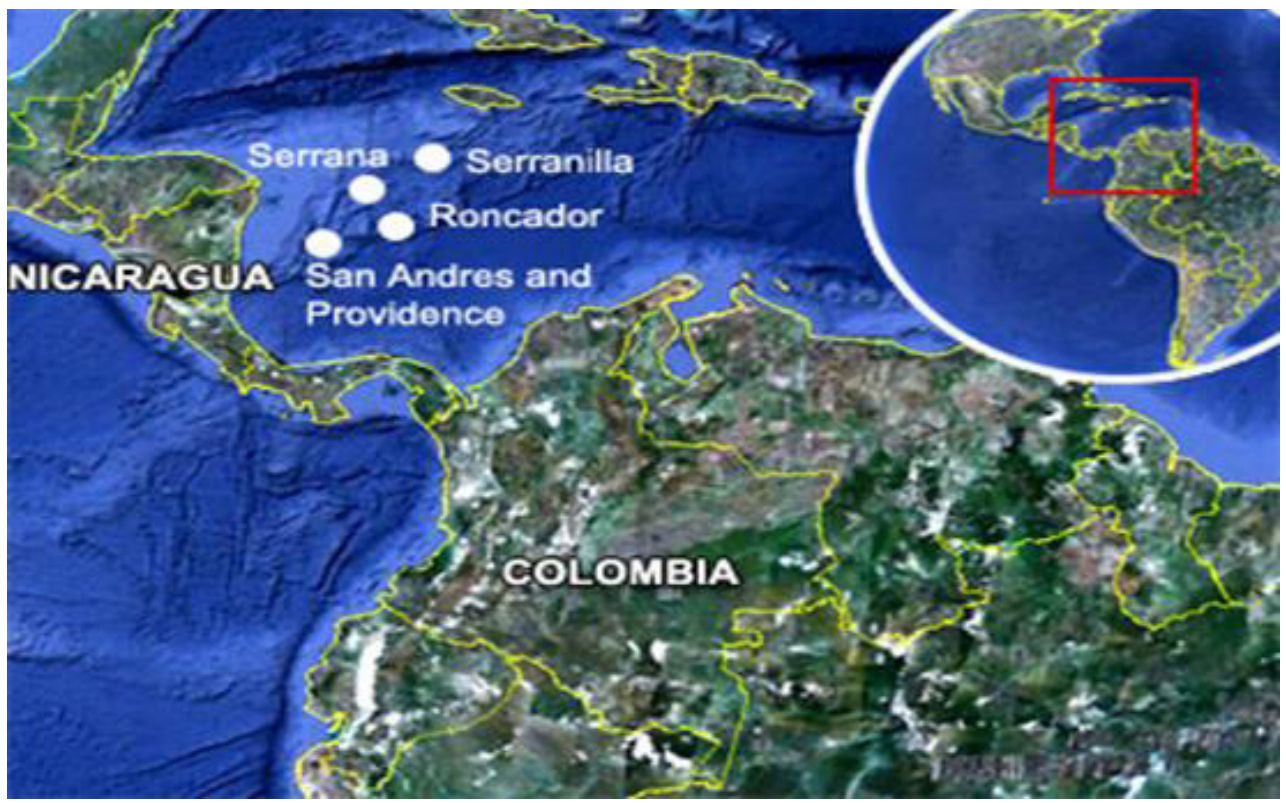

El tratado de 1972 provocó una vehemente reacción en Nicaragua, que de inmediato expresó su firme oposición ya que simbolizaba un golpe político a la dictadura somocista, fiel representante de los intereses de Estados Unidos en Nicaragua. A través del fuerte lobby que tenía en el Congreso norteamericano, Somoza logró evitar que el Senado estadounidense ratificara el tratado. Este fue el contexto que encontró la controversia la revolución popular sandinista (Dirección de Relaciones Internacionales Parlamentarias, 2012)

En los últimos meses de 1979 se planteó en la Cancillería de Nicaragua la preocupación por la defensa de los intereses territoriales del país y la voluntad de poner fin a 70 años de olvido y corrupción que amenazaban con hacer mayores las pérdidas territoriales de Nicaragua (Dirección de Relaciones Internacionales Parlamentarias, 2012).

El 4 de febrero de 1980, la Junta de Reconstrucción Nacional emite mediante Decreto No. 324, Declaración Sobre las Islas de San Andrés, Providencia y Territorios Circundantes, invalidando el Tratado Esguerra Bárcenas de 1928 y argumentando que durante el año de la firma del Tratado el país se encontraba ocupado militarmente por Estados Unidos (Asamblea Nacional, 1980). 


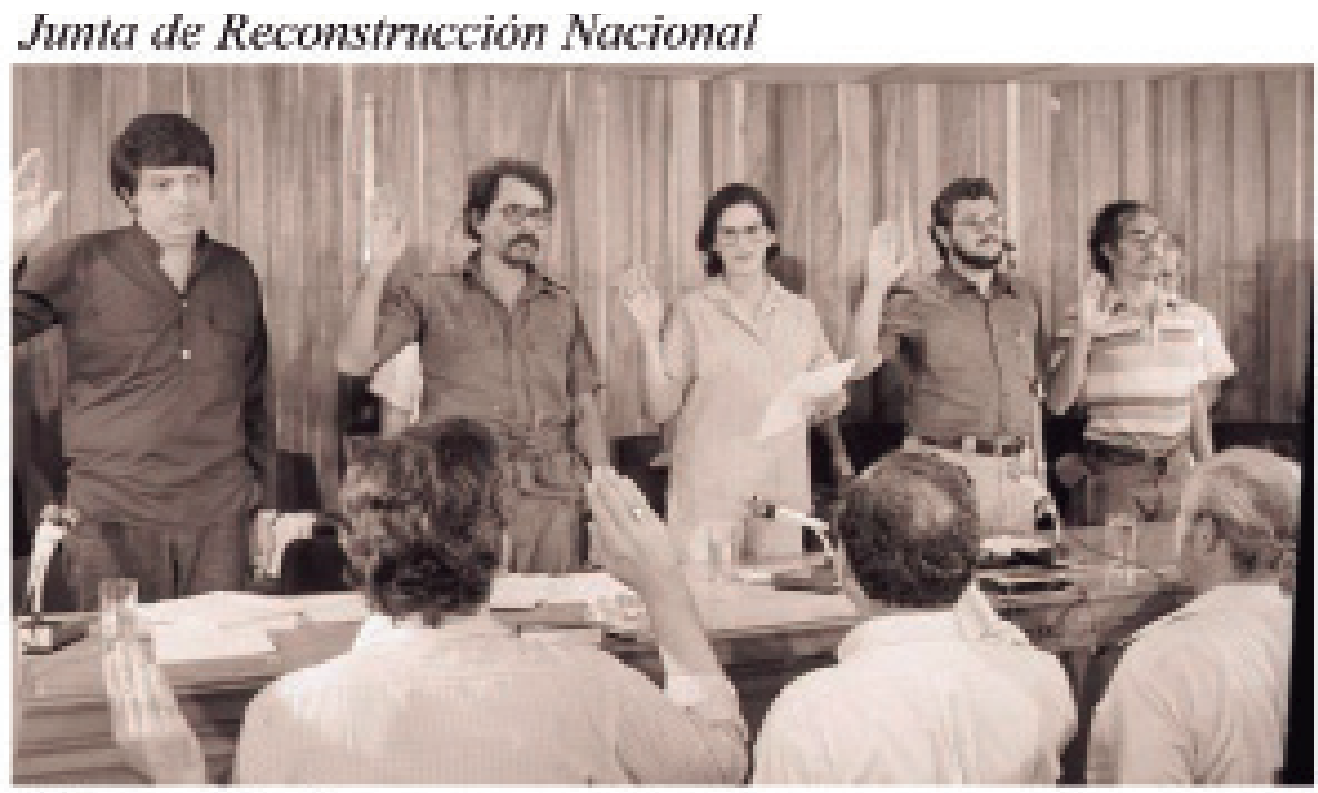

Fuente: (Redaccion, 2019)

2.2. Antecedes del conflicto 1803-1977
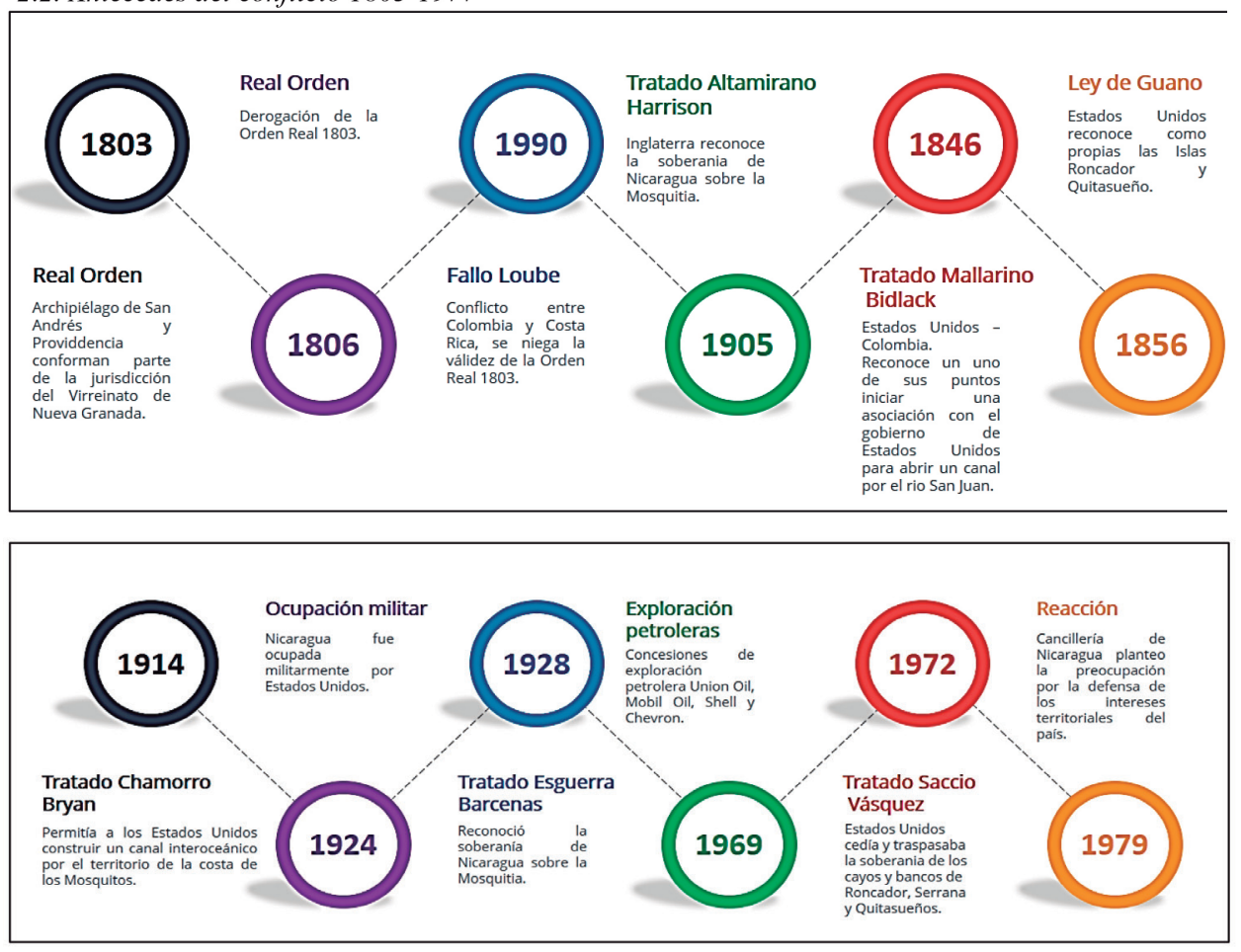

2.3 Cronología del Conflicto 
En esta sección presentamos la cronología del conflicto considerando el periodo de 1979 hasta 2012. Se mencionan los hechos más relevantes.

Tabla Cronología del conflicto. Fundamentos de hecho y de derecho sobre la controversia.

\begin{tabular}{|c|c|}
\hline $\mathbf{0}$ & \\
\hline & $\begin{array}{l}\text { icio de los estudios de la legalidad del tratado. Asimismo, de una política activa de } \\
\text { fensa de los derechos el país. Promulgación del Decreto No } 205 \text { de la Ley sobre } \\
\text { ataforma Continental y Mar Adyacente. }\end{array}$ \\
\hline 1980 & $\begin{array}{l}\text { laboración de un Libro Blanco } \\
\text { reivindicación de un territorio }\end{array}$ \\
\hline 81 & $\begin{array}{l}\text { Con la llegada de Ronald Reagan al poder significó el fin de cualquier posible } \\
\text { convivencia entre Estados Unidos y Nicaragua ya que el antisandinismo de Reagan } \\
\text { lo llevó a ratificar en } 1981 \text {, a petición del gobierno de Colombia, el tratado } \\
\text { SaccioVázquez Carrizosa de } 1972 \text {, "cediendo" Estados Unidos a Colombia los cayos } \\
\text { de Quitasueño, Roncador y Serrana. Más que un reconocimiento a los derechos de } \\
\text { Colombia, el acto era un castigo a la política nacional e independiente del gobierno } \\
\text { sandinista. }\end{array}$ \\
\hline 1982 & $\begin{array}{l}\text { Las relaciones entre Nicaragua y Colombia mejoraron con la Presidencia de Belisario } \\
\text { Betancur en } 1982 \text { ya que durante su mandato decidió rescatar a Colombia de su } \\
\text { sumisión a Estados Unidos y sacarla de su aislamiento en el entorno latinoamericano. }\end{array}$ \\
\hline 1986 & $\begin{array}{l}\text { El último año de la presidencia de Betancur se deterioraron las relaciones y en los } \\
\text { últimos días de su mandato, el } 2 \text { de agosto de 1986, el gobierno de Colombia suscribió } \\
\text { con el de Honduras el Tratado Ramírez-López Weitzel }{ }^{5} \text {, que pretendía cercenar } \\
\text { 130,000 kilómetros de mar a Nicaragua. }\end{array}$ \\
\hline 1990 & $\begin{array}{l}\text { El cambio de gobierno no significó un cambio de actitud ni en Colombia ni en } \\
\text { Nicaragua. El gobierno de Violeta Chamorro mantuvo la política territorial trazada } \\
\text { por el sandinismo, considerando nulos e inválidos todos los "tratados" fabricados por } \\
\text { Colombia en estos } 60 \text { años para despojar a los nicaragüenses de sus territorios. }\end{array}$ \\
\hline
\end{tabular}




\begin{tabular}{|c|c|}
\hline Año & \\
\hline 1998 & $\begin{array}{l}\text { El presidente Arnoldo Alemán renunció a la posibilidad de un acuerdo directo con } \\
\text { Colombia y anunció la intención de llevar el caso a la Corte Internacional de Justicia } \\
\text { de La Haya. }\end{array}$ \\
\hline 2001 & $\begin{array}{l}\text { El presidente Arnoldo Alemán renunció a la posibilidad de un acuerdo directo con } \\
\text { Colombia y anunció la intención de llevar el caso a la Corte Internacional de Justicia } \\
\text { de La Haya. } \\
\text { E1 } 5 \text { de diciembre de } 2001 \text {, anticipándose a la acción legal nicaragüense, el gobierno } \\
\text { colombiano se presentó ante la ante el Secretario General de Las Naciones Unidas, el } \\
\text { retiro de la competencia de la Corte Internacional de Justicia en lo que respecta a la } \\
\text { jurisdicción obligatoria. } \\
\text { El } 6 \text { de diciembre de } 2001 \text {, el gobierno de Nicaragua oficializó la demanda } \\
\text { reclamando ante la Corte Internacional de Justicia la soberanía sobre el Archipiélago } \\
\text { de San Andrés y Providencia y alegó que Colombia no tenía ningún título legal de } \\
\text { soberanía sobre el área. Nicaragua pidió a la Corte que se pronunciara sobre la } \\
\text { soberanía de las islas de San Andrés, Providencia y Santa Catalina, sobre la soberanía } \\
\text { de los Cayos Roncador, Serrana y Quitasueño y la delimitación de áreas marinas y } \\
\text { submarinas entre los dos países. Nicaragua reivindica su derecho a las islas sobre la } \\
\text { base de la Convención de Derecho del Mar. }\end{array}$ \\
\hline 2002 & $\begin{array}{l}\text { El } 17 \text { de julio de } 2002 \text {, el gobierno de Colombia anuncia el envío a Nicaragua de una } \\
\text { nota diplomática de protesta por la convocatoria de una licitación internacional para } \\
\text { otorgar concesiones petroleras en aguas del Caribe que están bajo jurisdicción } \\
\text { colombiana. }\end{array}$ \\
\hline 2003 & $\begin{array}{l}\text { El } 24 \text { de enero de } 2003 \text {, Nicaragua envía una nota de protesta formal a Colombia por } \\
\text { la publicación de un atlas con un mapa de ese país que "afecta la soberanía e integridad } \\
\text { territorial" de la nación centroamericana. }\end{array}$ \\
\hline 2004 & $\begin{array}{l}\text { E1 } 26 \text { enero de 2004, Nicaragua responde ante la Corte Internacional de Justicia las } \\
\text { objeciones de Colombia alegando que el Tratado al que hace referencia el Estado } \\
\text { colombiano fue firmado bajo ocupación de su territorio, por lo cual es inválido. }\end{array}$ \\
\hline 2007 & $\begin{array}{l}\text { El } 11 \text { de julio de 2007, Colombia argumenta en la primera audiencia ante la CIJ carece } \\
\text { de jurisdicción en la disputa presentada por Nicaragua sobre la frontera entre estos }\end{array}$ \\
\hline
\end{tabular}




\begin{tabular}{|l|l|}
\hline Año & $\begin{array}{l}\text { Descripción } \\
\text { dos países en el mar Caribe y pidió a los jueces que declararan "terminada" la } \\
\text { controversia. }\end{array}$ \\
\hline 2010 & $\begin{array}{l}\text { Los países vecinos Costa Rica y Honduras solicitaron a la Corte de la Haya, el } 25 \text { de } \\
\text { febrero y el } 10 \text { de junio respectivamente, participar en la tramitación del contencioso } \\
\text { porque consideraban que el posible fallo de la Corte podría afectar a sus intereses. }\end{array}$ \\
\hline 2011 & $\begin{array}{l}\text { En mayo de 2011, la Corte Internacional de Justicia rechaza las solicitudes de } \\
\text { intervención de Honduras y Costa Rica, las cuales retrasaron la fecha de inicio de las } \\
\text { audiencias orales. Nicaragua fue contraria a la intervención de Honduras y Costa Rica, } \\
\text { mientras que Colombia asumió una posición más favorable al respecto. }\end{array}$ \\
\hline $\mathbf{2 0 1 2}$ & $\begin{array}{l}\text { Debido al conflicto sobre la frontera marítima y terrestre entre los dos países, se } \\
\text { llevaron a cabo las audiencias orales en los meses de abril y mayo en la Corte de la } \\
\text { Haya, Nicaragua, el país demandante fue quien dio inicio a las audiencias el } 23 \text { de } \\
\text { abril por dos días. }\end{array}$ \\
\hline
\end{tabular}

Fuente: (Dirección de Relaciones Internacionales Parlamentarias, 2012)

\subsection{Proceso legal ante la Corte Internacional de Justicia}

En esta sección se describe la demanda, memorial de los argumentos presentados en el proceso por los equipos de expertos de Nicaragua y Colombia, ovedades del proceso y el diferendo que se basó en tres elementos principales: invalidez del Tratado Esguerra Barcenas de 1928, marco legal y proporcionalidad de recursos naturales y plataforma marítima. 
La intención nicaragüense de llevar el conflicto con Colombia ante la Corte Internacional de Justicia de La Haya se materializó con la Application Instituting Proceedings registrada oficialmente el 6 de diciembre de 2001, pero fueron necesarios diez años de litigio hasta que el 19 de noviembre de 2012 se profirió la sentencia.

Vista General de la Corte Internacional de Justicia

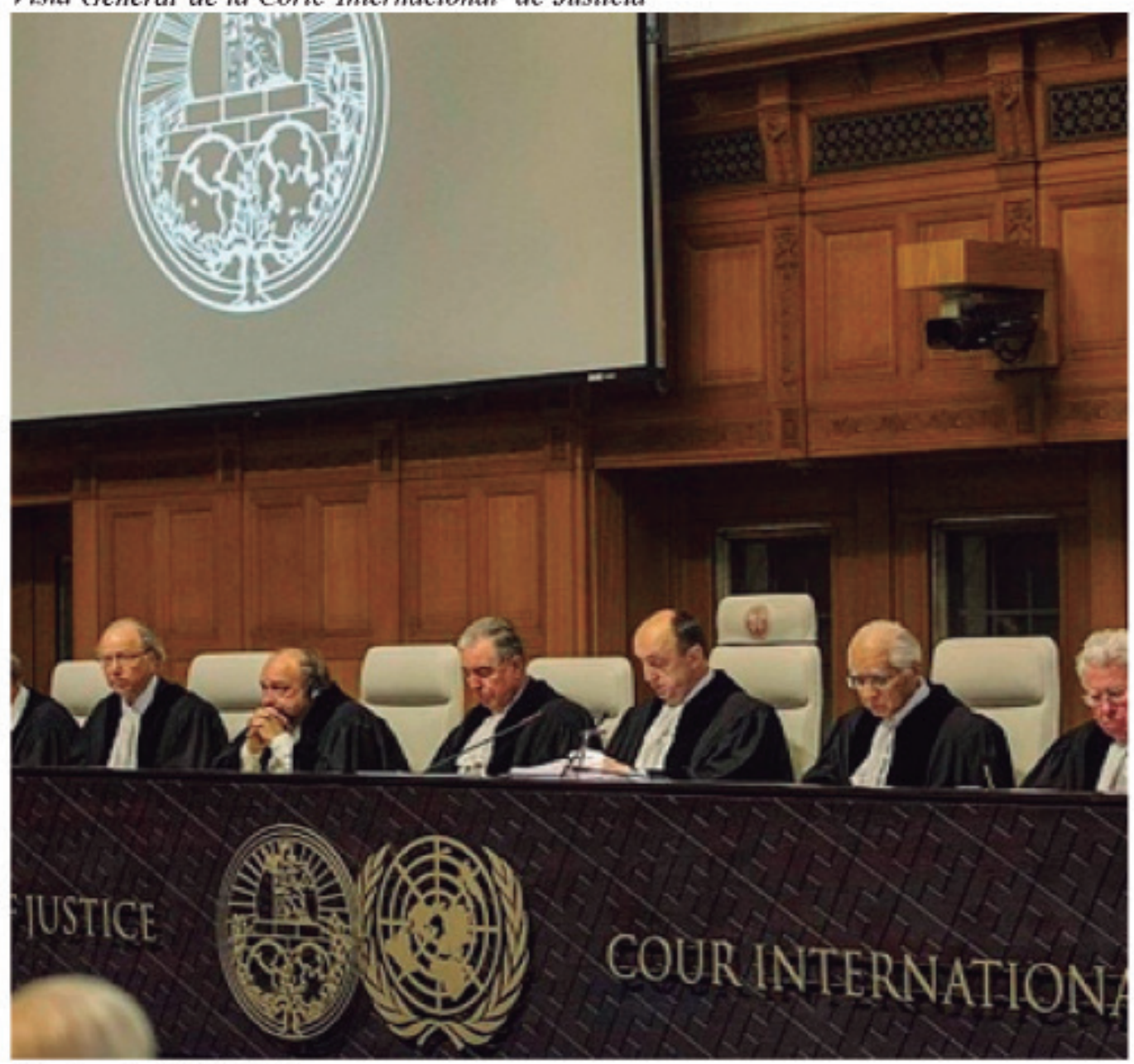

Fuente: (ius360, 2015) 


\subsubsection{Memoria y pretensiones del Estado de Nicaragua}

\subsection{Antecedentes}

Una vez admitido el caso en la Corte Internacional de Justicia se presentó el memorial nicaragüense el día 23 de abril de 2003; este documento se divide en tres partes, la primera conformada por los alegatos jurídicos sobre el derecho que tenía Nicaragua a poseer la costa de Mosquitos y las islas adyacentes bajo el principio del uti possidetis iuris, alegando que los mencionados territorios se encontraban bajo el dominio de la Capitanía General de Guatemala antes de la expedición de la Real Orden de 1803, que fue en argumentos de Nicaragua, revocada con posterioridad en el año de 1806; entendiendo además que la Real Orden de 1803 no consistía en un acto de transferencia territorial al Virreinato de la Nueva Granda, sino un mero acto administrativo de defensa de los territorios hispánicos en el antiguo régimen, por tal razón, para el gobierno de Nicaragua los territorios en disputa nunca salieron del dominio de la Capitanía de Guatemala y una vez efectuada la transición entre el antiguo régimen y los regímenes republicanos surgidos con la independencia, serían las repúblicas surgidas de la antigua capitanía quienes deberían dominar el archipiélago de San Andrés y Providencia y la costa de Mosquitos, y no el Virreinato de la Nueva Granada.

El segundo elemento que integra el memorial consiste en los argumentos contra la validez del Tratado Esguerra-Bárcenas de 1928. Frente a este alegato Nicaragua ya había sentado su posición desde que formuló su Libro Blanco en 1980. Para el entonces Frente de Liberación Nacional el tratado de 1928 era inválido porque iba en contra de la Constitución nicaragüense, y nulo porque para el momento de negociar el contenido del instrumento internacional el país se encontraba bajo la ocupación norteamericana; en este punto ya se pretendía desconocer por parte de Nicaragua el artículo 27 de la Convención de Viena que obliga a los estados a no excusarse en el derecho interno para ignorar sus obligaciones internacionales; similar argumento presentaría después el gobierno colombiano una vez conocido el contenido del fallo en 2012.

Como tercer y último punto de la memoria aparece la solicitud que se hizo a la Corte Internacional de Justicia para que delimitara la frontera marítima entre Nicaragua y Colombia.

El primer desafío de la representación nicaragüense fue el enfrentarse al hecho de que Colombia había ratificado la Convención sobre Plataforma Continental de la Organización de las Naciones Unidas, firmada en Ginebra en 1958, pero no era parte dela Convención sobre Derecho del Mar de 1982. A su vez, Nicaragua no había ratificado la Convención sobre Plataforma Continental, pero sí la que versa sobre Derecho del Mar, así que sustentó sus pretensiones en los principios generales de la delimitación marítima, pues los instrumentos ratificados por ambos países eran distintos y no podían interpretarse a través de la analogía. Así que la invocación a estos principios generales pretendía el uso de métodos históricamente empleados para la delimitación de fronteras marítimas; dichos principios además de no estar codificados, son adaptados a las situaciones concretas donde se busca una división proporcional de áreas marítimas y submarinas.

De esta forma Nicaragua reforzaba su posición sobre el punto que no se había definido de manera expresa en 1928, abriendo además la posibilidad a que la Corte decidiera a través de sus criterios de aplicación de los principios generales de la delimitación marítima, pues Colombia no se encontraba obligada por la Convención de Montego Bay sobre Derecho del Mar de 1982. A través de los tres elementos que integraron el escrito de alegatos nicaragüense discurrió el proceso; el siguiente punto a revisar serían los argumentos colombianos frente al diferendum, los cuales fueron presentados en 2003 ante la Corte. 


\subsubsection{Puntos torales del memorial nicaragüense}

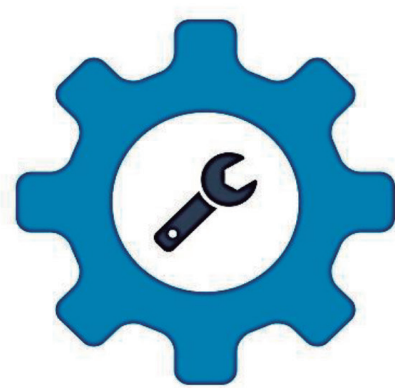

Principio de Uti Possidetis juris

Alegatos jurídicos sobre el derecho que tenía Nicaragua a poseer la costa de Mosquitos y las islas adyacentes.

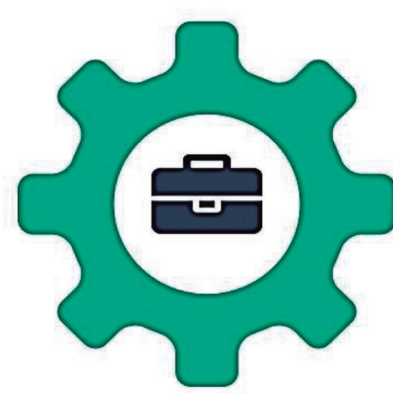

Tratado Esguerra Barcenas

Argumentos contra la invalidez del Tratado. Nicaragua habia sentado su posición desde que formula su Libro Blanco en 1980.

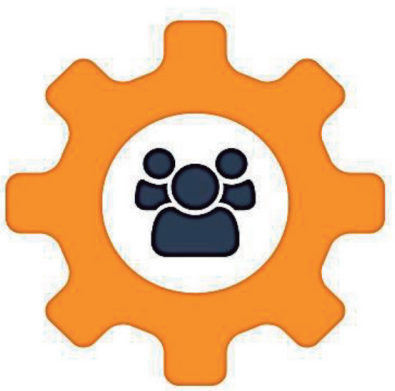

Solicitud CIJ

Solicitud que se hizo a la Corte Internacional de Justicia para que delimitara la frontera marítima entre Nicaragua y Colombia.

Fuente: Elaboración propia en base a (Alvarado Bedoya, 2014), (Dirección de Relaciones Internacionales Parlamentarias, 2012) y (Zamora, 2013)

\subsubsection{Memorial colombiano}

La reacción jurídica de Colombia ante el memorial nicaragüense se sustentó en dos líneas de trabajo, se atacó la competencia de la Corte a través de la formulación de excepciones previas y el fondo de la causa fue atacado a través de excepciones de mérito o de cargo.

Los agentes representantes del gobierno colombiano cuestionaron la competencia de la Corte en la medida en que los hechos objeto de controversia sucedieron antes del reconocimiento de competencia a través del Pacto de Bogotá en 1948 y los hechos generadores de la controversia se dieron en 1928 con la firma y ratificación del Tratado Esguerra-Bárcenas; además como segunda excepción se sustentó que la Corte no era competente en cuanto el dominio colombiano sobre el archipiélago de San Andrés y Providencia, por ser una causa "ended", concluida por medio del arreglo directo entre las partes con la negociación, firma y ratificación de un tratado sobre la materia.

Durante el año 2004 la Corte Internacional de Justicia conoció y decidió sobre las excepciones y contestaciones hechas por Colombia y Nicaragua. Ninguna de las partes modificó sus argumentos sobre la causa, los cuales se habían dado desde 1980 con la formulación de los respectivos libros blancos. En la 


\subsubsection{Puntos torales del memorial colombiano}

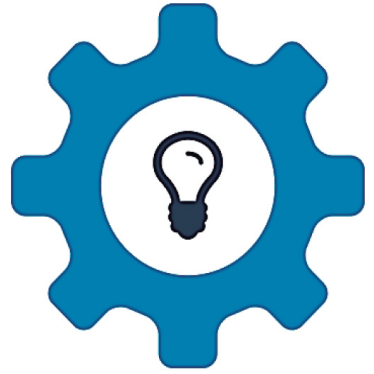

Competencia ClJ

Formulación de excepciones previas y el fondo de la causa fue atacado a través de excepciones de mérito o de cargo

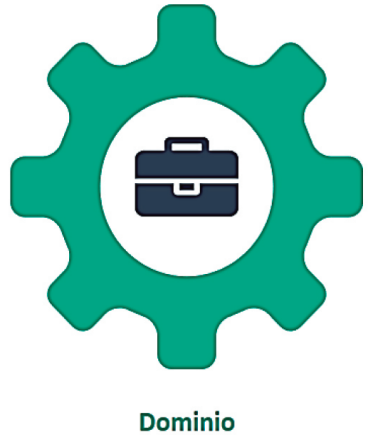

Sustentó que la Corte no era competente en cuanto el dominio colombiano sobre el archipiélago de San Andrés y Providencia, por ser una causa "ended".

Fuente: Elaboración propia en base a (Alvarado Bedoya, 2014), (Dirección de Relaciones Internacionales Parlamentarias, 2012) y (Zamora, 2013)

imagen siguiente se muestran las pretensiones de Nicaragua y Colombia durante el proceso en lo relacionado a la plataforma marítima.

2.4.6. Mapa que refleja las pretensiones de Nicaragua y Colombia, como la línea pondera trazada por la CIJ.

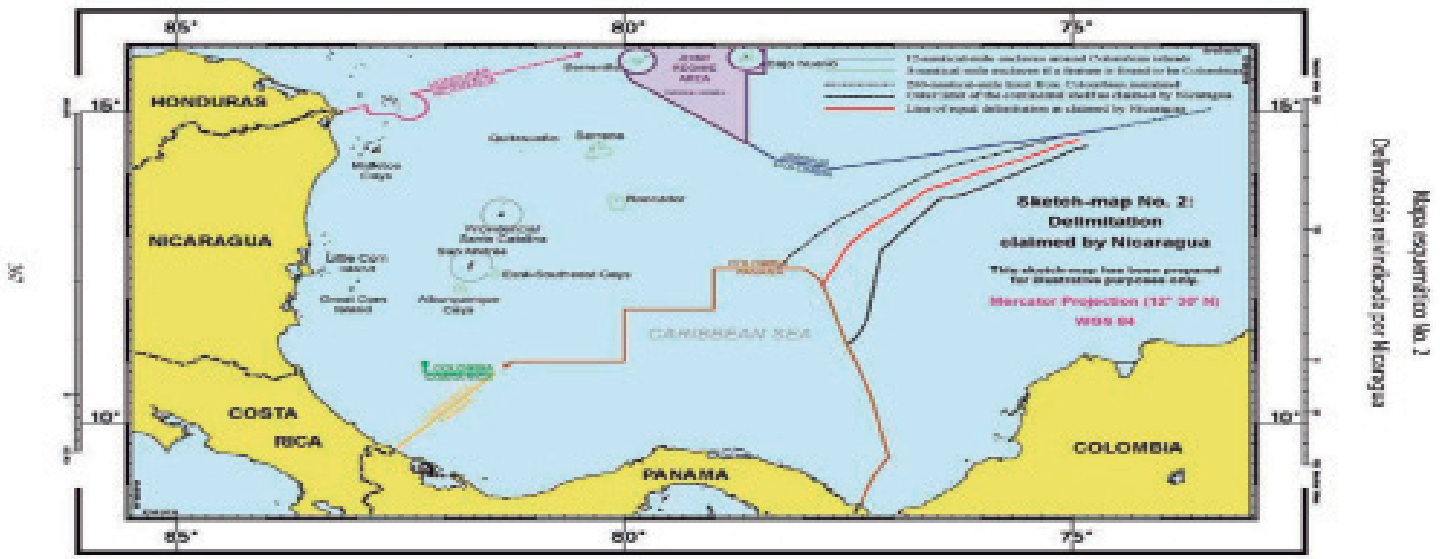

Fuente: dipublico.org 


\subsection{Novedad del proceso}

El 25 de febrero de 2010 se dio una importante suceso, en virtud del artículo 81 del reglamento de la Corte los gobiernos de Costa Rica y Honduras solicitaron permiso para intervenir dentro del proceso argumentando tener interés en el mismo debido a que compartían fronteras, tratados de delimitación e intereses en la causa; el tribunal escuchó los argumentos de partes e intervinientes, finalmente el 19 de noviembre de 2012 ya se contaba con el diferendo que dirimiría el conflicto que se había extendido por treinta años, y abriría un nuevo capítulo en el tema de disputas fronterizas y territoriales en la cuenca del Caribe.

\subsubsection{Diferendo}

El 19 de noviembre de 2012, la Corte Internacional de Justicia dictó su fallo en la causa relativa a la controversia territorial y marítima (Nicaragua contra Colombia) (Corte Internacional de Justicia, 2012).

La Corte estaba integrada en la forma siguiente: Presidente, Tomka; Vicepresidente, Sepúlveda-Amor; Magistrados, Owada, Abraham, Keith, Bennouna, Skotnikov, Cançado Trindade, Yusuf, Greenwood, Xue, Donoghue y Sebutinde; Magistrados ad hoc, Mensah y Cot; Secretario, Couvreur.

Un hecho destacable consiste en la composición de los equipos de litigio. La cualificación de los abogados y consejeros nicaragüenses fue mucho más alta que la del equipo colombiano, los litigios internacionales exigen un rigor y una cualificación técnica que difícilmente puede improvisarse. De los equipos jurídicos de cada país participaron en los alegatos orales, hechos entre el 23 de abril y el 4 de mayo de 2012, por Nicaragua el Honorable Embajador Carlos José Argüello Gómez y los señores abogados Alex Oude Elfernick, Antonio Remiro Brotóns, Alain Pellet, Robin Cleverly, Vayughan Lowe, Paul Reichler; en la representación de Colombia se encontraba el Honorable Embajador Julio Londoño Paredes y los señores abogados James Crawford, Marcelo Kohen y Rodman R. Bundy (Alvarado Bedoya, 2014).

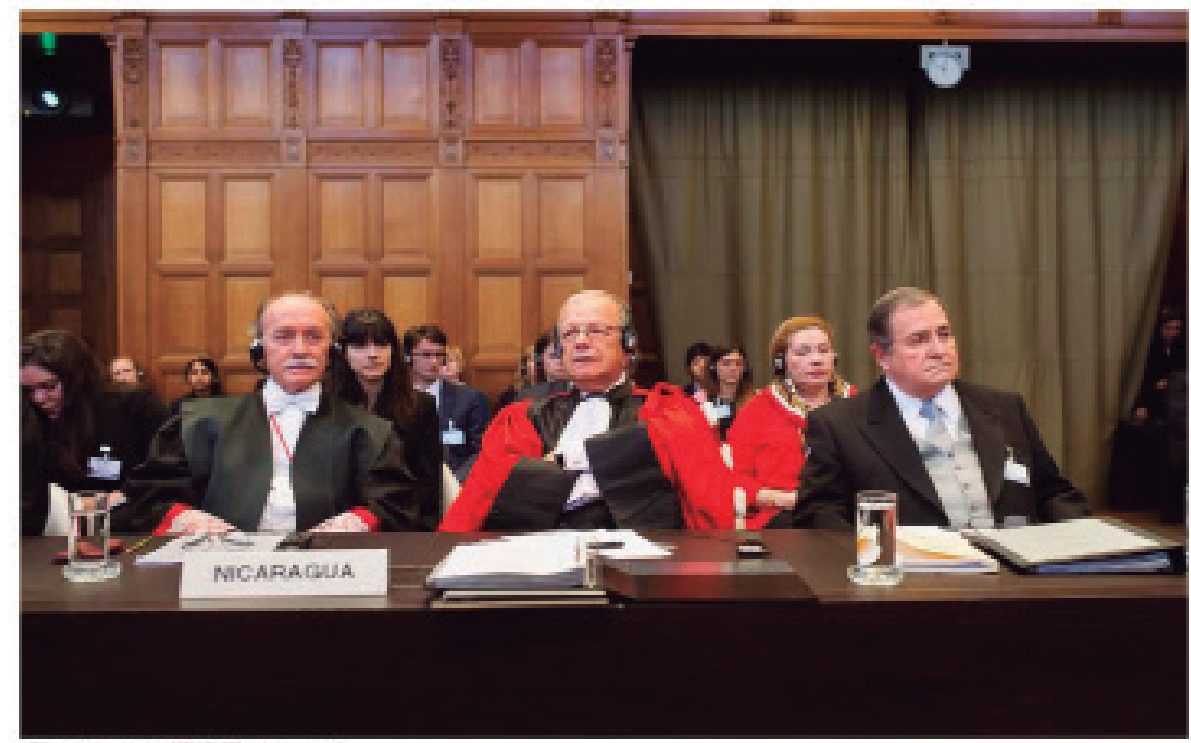

Fuente : (EFE, 2015) 
El agente de Nicaragua ante la Corte Internacional de Justicia (CIJ), Carlos José Argüello Gómez, en la audiencia preliminar sobre la disputa limítrofe que enfrenta a Colombia y Nicaragua.

Una vez oídos los alegatos de las partes los jueces de la Corte Internacional de Justicia tomaron su decisión usando como puntos de análisis tres elementos fundamentales (Corte Internacional de Justicia, 2012):

1) El argumento nicaragüense de la invalidez del Tratado Esguerra-Bárcenas de 1928 tema que no fue objeto de una profunda discusión en el diferendo, respecto al tema del uti possidetis iuris invocado por ambas partes en sus alegatos, para Colombia la Corte consideró que la Real Orden de 1803 efectivamente había puesto bajo el control y protección del Virreinato de la Nueva Granada el archipiélago de San Andrés y Providencia, como también los cayos e islotes que lo conformaban, además aunque Nicaragua había alegado que existió una Real Orden en 1806 que denegó la primera orden, para la Corte con el arbitramento del presidente de la república francesa, Emile Loubet, el 11 de septiembre de 1910 se confirmó la validez de la orden de 1803, además la Corte agregó que en el Antiguo Régimen era la Capitanía General quien tenía antes la jurisdicción sobre el archipiélago y que por orden directa de Su Majestad el Rey se había trasladado dicho control al Virreinato por encontrarse en mejores condiciones de responder a un ataque de los ingleses. Sin embargo, también se definió que el principio del uti possideris juris no podía ser aplicado respecto al mar Caribe, pues no se refería de manera expresa al área marítima en disputa.

2) El derecho aplicable a la causa no era ni la Convención sobre Derecho del Mar de 1982, ni la Convención sobre Plataforma Continental de 1958, así que las partes aceptaron que el derecho aplicable era la costumbre internacional del mar, y aunque Colombia había ejercido actos de soberanía durante algo más de cincuenta años sobre el meridiano 82, las mismas costumbres internacionales establecían que había una disparidad entre las distancias de las costas de ambos países respecto a la frontera (Corte Internacional de Justicia, 2012).

3) El equitativo acceso a los recursos naturales, y aplicando un test de proporcionalidad territorial llegó a la conclusión de que existía una desproporcionada repartición de las áreas marítimas y por tal razón entró a fijar una nueva área de territorio marítimo para Nicaragua superior a 75.000 km2.

\subsection{Elementos de análisis del fallo}

La Corte decidió la soberanía de Colombia sobre las islas de Alburquerque, Bajo
Nuevo, Sureste, Quitasueño, Roncador, Serrana y Serranilla y, asimismo, se declaró
admisible la petición de Nicaragua en orden a que la Corte decidiera la forma apropiada de
delimitación marítima, en el marco geográfico y juridico constituido por
las costas continentales de Nicaragua y Colombia, dividiendo por partes iguales los
derechos superpuestos a la plataforma continental de ambas partes; de esa forma, el fallo
estableció una linea de frontera marítima única entre ambos países, que delimita la
plataforma continental y las zonas económicas exclusivas, según líneas geodésicas que
unen los puntos con coordenadas, indicadas detalladamente y, además, determinó una
frontera marítima única de enclave alrededor de las islas de Quitasueño y de Serrana (Corte
Internacional de Justicia, 2012).


La línea de la frontera marítima única que delimita la plataforma continental y las zonas económicas exclusivas de la República de Nicaragua y la República de Colombia seguirá las líneas geodésicas que conectan los puntos con las coordenadas siguientes:
1. $13^{\circ} 46^{\prime} 35.7^{\prime \prime}$
$81^{\circ} 29^{\prime} 34.7^{\prime \prime}$
2. $13^{\circ} 31^{\prime} 08.0^{\prime \prime}$
$81^{\circ} 45^{\prime} 59.4^{\prime \prime}$
3. $13^{\circ} 03^{\prime} 15.8^{\prime \prime}$
$81^{\circ} 46^{\prime} 22.7^{\prime \prime}$
4. $12^{\circ} 50^{\prime} 12.8^{\prime \prime}$
$81^{\circ} 59^{\prime} 22.6^{\prime \prime}$
5. $12^{\circ} 07^{\prime} 28.8^{\prime \prime}$
$82^{\circ} 07^{\prime} 27.7^{\prime \prime}$
6. $12^{\circ} 00^{\prime} 04.5^{\prime \prime}$
$81^{\circ} 57^{\prime} 57$.

\subsection{Nueva plataforma maritima de Nicaragua}

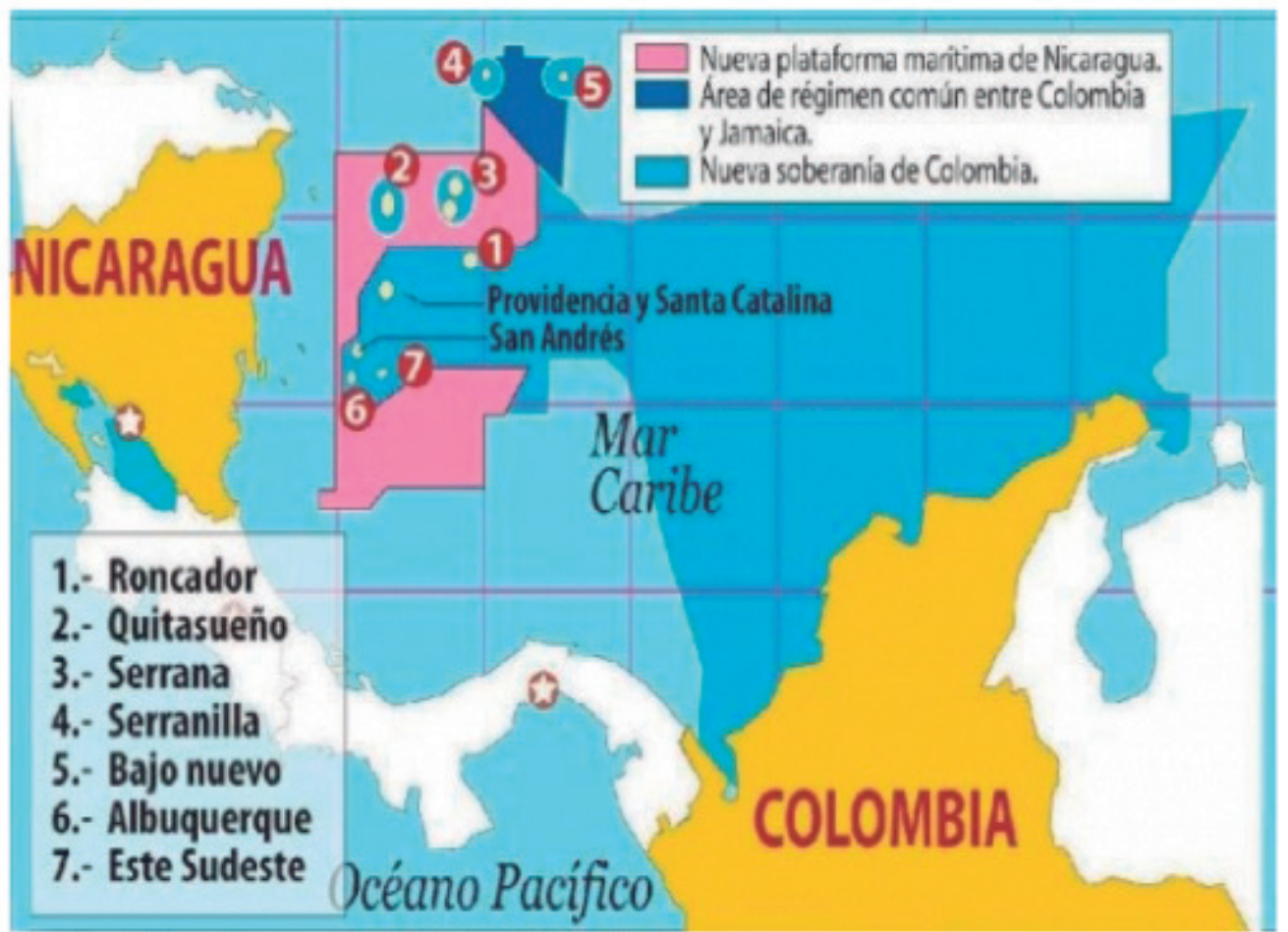

Fuente: (Corte Internacional de Justicia, 2012) 


\subsubsection{Consecuencia de la sentencia}

En esta sección listamos de forma concisa las consecuencias de la resolución a nivel nacional e internacional: Las decisiones de la Corte Internacional de Justicia no son apelables, no hay segunda instancia. No hay forma jurídica de reversar la situación, en base a lo anterior se modifican los mapas de Nicaragua y Colombia acatando el dictamen de la Corte Internacional de Justicia.

- En Nicaragua el fallo promovió una gran unidad entre todos los nicaragüenses y fue recibido con gran alegría (La Voz del Sandinismo, 2012).

- La reacción del gobierno del presidente Juan Manuel Santos y la de su ministra de Relaciones Exteriores fue la de salir al paso con peticiones al señor Secretario General de las Naciones Unidas Ban Ki-moon para que "conociera de primera mano" las "inmensas implicaciones de este fallo", aun cuando el Secretario General no puede intervenir de ninguna manera en las decisiones que toma un tribunal internacional (Alvarado Bedoya, 2014).

- Nicaragua presentara ante la Corte Internacional de Justicia una nueva queja por el incumplimiento al fallo que es vinculante e inapelable.

- Colombia se retira del Pacto de Bogotá, que reconoce la jurisdicción de la Corte Internacional de Justicia (CIJ) de La Haya, en rechazo del fallo que definió nuevos límites marítimos con Nicaragua (EFE, 2012).

\subsubsection{Celebración de la sentencia de la CIJ en Nicaragua}

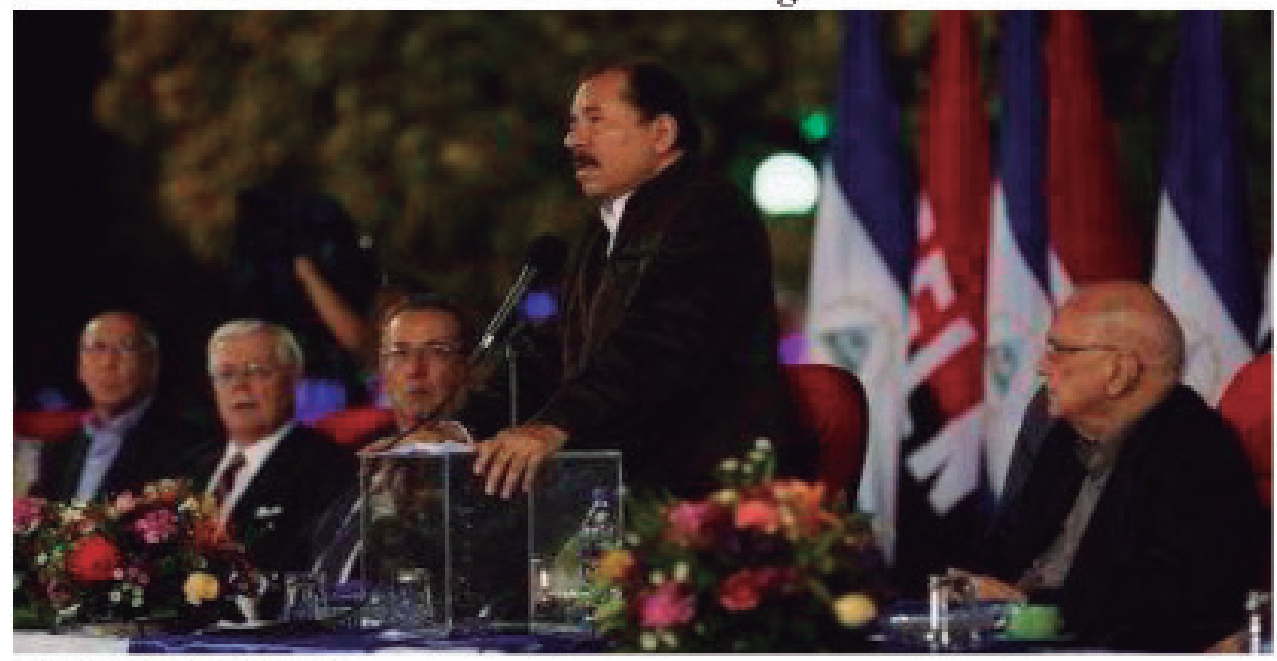

Finente: (AGATON, 20I2)

El Presidente del Estado de Nicaragua, quien impulsó las pretensiones ante la Haya, apegados al derecho internacional, se reúne y da el mensaje al soberano pueblo sobre el compromiso de la clase política nicaragüense, de defender la sentencia de la Corte Internacional de Justicia del 19 de noviembre de 2012. Porque es un territorio del Pueblo, refería el mandatario de Nación Centroamérica. 
El Estado de Nicaragua es uno de los estados que más ha recurrido a la jurisdicción de derecho internacional público de la Haya, legitimando los procedimientos jurídicos, para dirimir por las vías del derecho, cualquier conflicto con otros estados.

\section{Conclusiones}

En suma, en esta sistematización jurídica sobre el conflicto marítimo entre Nicaragua y Colombia se llegaron a las conclusiones siguientes:

- Durante el periodo de 1803 hasta 1979 se dieron una serie de incidentes que fueron los catalizadores de que Nicaragua se viera obligado a imponer una demanda ante la $\mathrm{ClJ}$ en el xx. Dentro de los más relevantes podemos mencionar: La antigua costa de los Mosquitos, incluyendo las islas adyacentes del archipiélago de San Andrés y Providencia que durante la colonia habían permanecido bajo la jurisdicción de la Capitanía General de Guatemala (1803); La Orden Real de 1806 que invalido la Orden Real de 1803; la disputa entre Colombia y Gran Bretaña a lo largo del siglo XIX por el control de la Costa de Mosquitos y el acceso al río San Juan, zonas indispensables para la construcción del canal interoceánico en Nicaragua; Ley de Guao (1856), Nicaragua arrienda las islas del Mangle (Chico y Grande) por 99 años a los Estados Unidos mediante el Tratado Chamorro - Weitzel (1913), Firma del Tratado firma el Tratado Chamorro - Bryan (1914), Ocupación militar norteamericana(1924), firma del Tratado Esguerra Barcenas (1928), Guerra civil (1979); y Decreto No. 324: Declaración Sobre las Islas de San Andrés, Providencia y Territorios Circundantes, invalidando el Tratado Esguerra - Bárcenas de 1928.

- Dentro de los hechos que más sobresalen en la cronología de los hechos están la promulgación del Decreto No .205 de la Ley sobre Plataforma Continental y Mar Adyacente, Libro Blanco y rectificación del Tratado SaccioVázquez Carrizosa (1981).

- El 6 de diciembre de 2001, el gobierno de Nicaragua oficializó la demanda reclamando ante la Corte Internacional de Justicia la soberanía sobre el Archipiélago de San Andrés y Providencia y alegó que Colombia no tenía ningún título legal de soberanía sobre el área. Nicaragua pidió a la Corte que se pronunciara sobre la soberanía de las islas de San Andrés, Providencia y Santa Catalina, sobre la soberanía de los Cayos Roncador, Serrana y Quitasueño y la delimitación de áreas marinas y submarinas entre los dos países. Nicaragua reivindica su derecho a las islas sobre la base de la Convención de Derecho del Mar.

- La estrategia del equipo nicaragüense se basó en tres pilares: alegatos jurídicos sobre el derecho que tenía Nicaragua a poseer la costa de Mosquitos y las islas adyacentes bajo el principio del uti possidetis iuris; argumentos contra la validez del Tratado Esguerra-Bárcenas de 1928 y solicitud que se hizo a la Corte Internacional de Justicia para que delimitara la frontera marítima entre Nicaragua y Colombia.

- La estrategia legal se basó en dos la competencia de la Corte a través de la formulación de excepciones previas y el fondo de la causa fue atacado a través de excepciones de mérito o de cargo; y el cuestionamiento de la competencia de la Corte en la medida en que los hechos objeto de controversia sucedieron antes del reconocimiento de competencia a través del Pacto de Bogotá en 1948.

- El 25 de febrero de 2010 se dio un importante suceso, en virtud del artículo 81 del reglamento de la Corte los gobiernos de Costa Rica y Honduras solicitaron permiso para intervenir dentro del proceso 
argumentando tener interés en el mismo debido a que compartían fronteras, tratados de delimitación e intereses en la causa.

- Un hecho destacable consiste en la composición de los equipos de litigio. La cualificación de los abogados y consejeros nicaragüenses fue mucho más alta que la del equipo colombiano, los litigios internacionales exigen un rigor y una cualificación técnica que difícilmente puede improvisarse.

- Los jueces de la Corte Internacional de Justicia tomaron su decisión usando como puntos de análisis tres elementos fundamentales: El argumento nicaragüense de la invalidez del Tratado EsguerraBárcenas de 1928 tema que no fue objeto de una profunda discusión en el diferendo, respecto al tema del uti possidetis iuris; El derecho aplicable a la causa no era ni la Convención sobre Derecho del Mar de 1982, ni la Convención sobre Plataforma Continental de 1958, así que las partes aceptaron que el derecho aplicable era la costumbre internacional del mar; $y$ el equitativo acceso a los recursos naturales, y aplicando un test de proporcionalidad territorial

- La Corte decidió la soberanía de Colombia sobre las islas de Alburquerque, Bajo Nuevo, Sureste, Quitasueño, Roncador, Serrana y Serranilla y, asimismo, se declaró admisible la petición de Nicaragua en orden a que la Corte decidiera la forma apropiada de delimitación marítima, en el marco geográfico y jurídico constituido por las costas continentales de Nicaragua y Colombia, dividiendo por partes iguales los derechos superpuestos a la plataforma continental de ambas partes; de esa forma, el fallo estableció una línea de frontera marítima única entre ambos países, que delimita la plataforma continental y las zonas económicas exclusivas, según líneas geodésicas que unen los puntos con coordenadas, indicadas detalladamente y, además, determinó una frontera marítima única de enclave alrededor de las islas de Quitasueño y de Serrana (Corte Internacional de Justicia, 2012).

- Dentro de las consecuencias más relevantes después de la sentencia de la CIJ están: La reacción del gobierno del presidente Juan Manuel Santos y la de su ministra de Relaciones Exteriores fue la de salir al paso con peticiones al señor Secretario General de las Naciones Unidas Ban Ki-moon; Nicaragua presentara ante la Corte Internacional de Justicia una nueva queja por el incumplimiento al fallo que es vinculante e inapelable; y Colombia se retira del Pacto de Bogotá, que reconoce la jurisdicción de la Corte Internacional de Justicia (CIJ) de La Haya, en rechazo del fallo que definió nuevos límites marítimos con Nicaragua.

- Cabe destacar que el Estado de Colombia se encuentra en desacato parcial en el 2021, es decir, que las estrategias dentro del Juicio ante la Corte de la Haya fuese técnica jurídica, sigue siendo una estrategia política y geo-estratégica de la clase política del Estado del Sur. 


\section{Referencias bibliográficas.}

- $\quad$ AGATON. (20 de noviembre de 2012). Victoria de Nicaragua, Colombia debe acatar. Recuperado el 30 de octubre de 2020, de https://carlosagaton.blogspot.com/2012/11/victoria-de-nicaragua-colombiadebe.html

- $\quad$ Alvarado Bedoya, O. A. (25 de Mayo de 2014). El conflicto fronterizo entre Colombia y Nicaragua: Recuento histórico de una lucha por el territorio. SciELO (scientific electronic library online), IX(25), 241-271. Recuperado el 28 de Octubre de 2020, de http://www.scielo.org.co/pdf/hisca/v9n25/v9n25a09.pdf

- $\quad$ Asamblea Nacional. (1928). Instrumento de Ractificación (Tratado entre Nicaragua y Colombia). Managua, Nicaragua: Asamblea Nacional. Recuperado el 29 de Octubre de 2020, de http://legislacion. asamblea.gob.ni/normaweb.nsf/(\$All)/B2DEA9985D263A09062574E900780F6B?OpenDocument

- Asamblea Nacional. (1980). Declaración sobre las Islas de San Andres, Providencia y Territorios Circudantes. Managua, Nicaragua: Publicado en La Gaceta No. 51 de 29 de febrero de 1980. Recuperado el 29 de Octubre de 2020, de http://legislacion.asamblea.gob.ni/normaweb.nsf/ (\$All)/571DF0EB782B1754062570A10057E6E3?OpenDocument

- $\quad$ Barbosa Miranda, F. J. (2003). El conflicto territorial entre Nicaragua y Honduras concerniente al paralelo 15 o y a la bisectriz en dirección al paralelo 17o. Revista Encuentro UCA, 58-77. Obtenido de https:// www.uca.edu.ni/2/images/Revista-Encuentro/Revistas/e65/art-3.pdf

- Corte Internacional de Justicia. (19 de noviembre de 2012). Derecho Interancional. Obtenido de 195. Controversia territorial y delimitación marítima (Nicaragua contra Colombia): https://www.dipublico. org/cij/doc/195.pdf

- Dirección de Relaciones Internacionales Parlamentarias. (2012). Cronología del Conflicto Limitrofe entre la República de Nicaragua y la República de Colombia. Managua, Nicaragua: Asamblea Nacional de Nicaragua. Recuperado el 28 de Octubre de 2020, de http://legislacion.asamblea.gob.ni/ Internacionales.nsf/3c1dc02306ef1c66062576c60058ae43/a9b886cdb89941e506257abe00563635/\$FILE/ Consolidado\%20Conflicto\%20Limitrofe\%20Nicaragua\%20Colombia13112012.pdf

- $\quad$ EFE. (29 de noviembre de 2012). Colombia se retira del Pacto de Bogotá. Portafolio. Recuperado el 30 de octubre de 2020, de https://www.portafolio.co/economia/finanzas/colombia-retira-pactobogota-116134

- $\quad$ EFE. (30 de septiembre de 2015). Confidencial. Obtenido de Colombia solicita que la demanda de Nicaragua ante la CIJ sea desestimada: https://confidencial.com.ni/arguello-malabarismo-juridico-decolombia/

- La Prensa. (11 de febrero de 2019). La Prensa. Recuperado el 30 de Noviembre de 2020, de https:// www.laprensa.com.ni/2019/02/11/politica/2523027-colombia-presenta-su-defensa-en-el-litigio-connicaragua-por-delimitacion-de-plataforma-continental 
- $\quad$ La Voz del Sandinismo. (19 de noviembre de 2012). Victoria de Nicaragua Unidad Nacional alrededor del fallo histórico en la Haya. Obtenido de https://www.lavozdelsandinismo.com/ nicaragua/2012-11-19/victoria-de-nicaragua-unidad-nacional-alrededor-del-fallo-historico-en-la-haya/

- $\quad$ Navarrete, J. (2019). La huella de los marines en Nicaragua. Magazine. Recuperado el 31 de octubre de 2020, de https://www.laprensa.com.ni/magazine/reportaje/la-huella-de-los-marines-ennicaragua/

- Redacción. (18 de julio de 2019). Revolución Sandinista: 4 claves para entender la última revolución armada de América Latina y lo que queda de su legado en Nicaragua. Obtenido de BBC News Mundo: https://www.bbc.com/mundo/noticias-america-latina-49035196

- Revista Conservadora. (1964). Los cuatro tratados canaletos. Revista Conservadora, 21. Recuperado el 31 de octubre de 2020, de https://www.enriquebolanos.org/data/docs/RC_1964_03_N42/ files/assets/downloads/publication.pdf

- $\quad$ Ruiza, M., Fernandez, T., \& Tamano, E. (31 de octubre de 2020). Biografia de Anastasio Somoz. Obtenido de Biografías y Vidas. La enciclopedia biográfica en línea.: https://www.biografiasyvidas.com/ biografia/s/somoza_anastasio.htm

- $\quad$ Turbout, F., \& Toro-Pérez, C. (s.f.). Atlas Caribe. Obtenido de Mosquitia protectorado Inglés en colonias "independizadas": http://atlas-caraibe.certic.unicaen.fr/es/page-311.html

- $\quad$ Witker, J., \& Larios, R. (1997). Metodología jurídica.

- Zamora, A. (2013). El Litigio Territorial Colombia. Revista Envío(154), 25. Recuperado el 29 de octubre de 2020, de https://www.envio.org.ni/articulo/900 